\title{
O PLANO MUNICIPAL DE EDUCAÇÃO: Da autonomia construída à autonomia decretada
}

\author{
Leandro Vitoriano da Silva \\ Maria Eliza Nogueira Oliveira ${ }^{(*)}$
}

Historicamente, a educação brasileira foi margeada pela problemática da dificuldade de acesso e permanência na escola. Apenas a partir do final da década de 1980, com a promulgação da Constituição Federal de 1988, este quadro passou a sofrer mudanças significativas e o processo de escolarização passou a ganhar ênfase e contornos mais sólidos, culminando na atual Lei de Diretrizes e Bases da Educação Nacional (Lei 9.394/96) que reorganizou o ensino brasileiro e motivou mudanças substantivas nos critérios de redistribuição e financiamento da educação, ampliando o ensino obrigatório. Ainda neste contexto, destacam-se outras políticas como a ampliação do Ensino Fundamental de nove anos e a obrigatoriedade da escolaridade dos seis aos dezessete anos (Emenda Constitucional 59/2009), que resultaram na Lei 12.796/2013 responsável pela ampliação da escolarização obrigatória a partir dos quatro anos de idade, tornando toda a Educação Básica de matrícula obrigatória e oferta gratuita.

Outro avanço, igualmente notório, no processo de ampliação do acesso à escola, diz respeito à criação do Fundo de Manutenção e Desenvolvimento do Ensino Fundamental (Fundef), substituído, posteriormente, pelo Fundo de Manutenção e Desenvolvimento da Educação Básica (Fundeb), que reestabeleceu critérios de financiamentos e possibilitou a implantação de novas políticas públicas num processo redistributivo.

Apesar dos direitos conquistados, o atual quadro educacional ainda carece de políticas públicas efetivas que auxiliem tanto na garantia da oferta do ensino quanto na permanência dos alunos na escola. Urge, portanto, a retomada de um planejamento efetivo visando ao aprimoramento dos aspectos quantitativos e qualitativos, pois não basta aumentar o número de ocupantes nas cadeiras escolares, antes, é necessário pensar na oferta de um ensino de qualidade que, dentre outras contribuições, venha a reduzir as desigualdades sociais no cenário brasileiro e fomentar a

\footnotetext{
${ }^{(*)}$ Leandro Vitoriano da Silva. Mestrando do Programa de Pós-Graduação em Educação da Universidade do Oeste Paulista (UNOESTE), membro do Grupo de Estudo e Pesquisa "Instituição Educacional: Organização e Gestão". Email: leovitoriano@hotmail.com.

Maria Eliza Nogueira Oliveira. Docente do Programa de Pós-graduação em Educação da Universidade do Oeste Paulista (Unoeste), membro do Grupo de Estudo e Pesquisa "Instituição Educacional: Organização e Gestão". E-mail: mariaeliza_oliveira@yahoo.com.br.
} 
participação política, visando reestabelecer os princípios democráticos primordiais à garantia dos direitos básicos de todos os cidadãos, em que se inclui o direito à educação.

Diante deste desafio, após alguns anos de discussão e tramitação no âmbito legislativo, aprovou-se a Lei 13.005/2014 que institui o novo Plano Nacional de Educação (PNE), ${ }^{1}$ cujas metas geraram impactos imediatos para a Educação Pública em todo o país. Neste texto, buscaremos refletir acerca do impacto do PNE no âmbito dos municípios, diante da exigência de formulação dos chamados Planos Municipais de Educação (PME) como instrumento indispensável ao alcance das metas propostas no documento federal, com seus principais óbices e contradições.

\section{A TRAJETÓRIA DO PNE NA ESFERA LEGAL: DO CONTEXTO AO TEXTO}

Nesta seção, pretendemos apresentar, brevemente, a trajetória de elaboração do Plano Nacional de Educação (PNE), com o objetivo de contextualizar este documento que, há mais de meio século, vem sendo apresentando como projeto permanente de definições de estratégias em busca da melhoria do ensino público em âmbito nacional. Nosso objetivo, neste primeiro momento, é refletir acerca dos acontecimentos que recolocaram em evidência o PNE na esfera legal para, num segundo momento, refletirmos acerca dos possíveis impactos e desafios que o novo PNE tem gerado no âmbito da gestão dos sistemas municipais de ensino.

A emergência de discussão mais efetiva em torno da necessidade de fixação de um plano nacional de educação, em uma perspectiva histórica, pode ser situada na década de 1930, mais especificamente, no Artigo 150 da "Constituição da República dos Estados Unidos do Brasil” de 16 de julho de 1934. Além de atribuir à União a competência de "fixar o plano nacional de educação", compreendendo todos os graus e ramos do ensino, comuns e especializados, o artigo da Lei reforçou a incumbência da União de "coordenar e fiscalizar a sua execução", em todo o território do país

Aprovada no contexto em que o acesso à educação escolar ainda não havia se estendido a uma camada significativa da sociedade, a lei previu a fixação de um plano nacional, mas não chegou a instituir um conjunto de metas visando à sua materialização, no sentido de conferir-lhe um status de obrigatoriedade em termos de execução por parte dos sistemas de ensino ${ }^{2}$. Todavia, tratou-

\footnotetext{
${ }^{1}$ Por ser aprovado em 2014, ou seja, historicamente recente, existem poucos autores que abordam esta temática, e ainda muitos deles, pelo pouco tempo de produção científica o fazem de modo muito superficial.

${ }^{2}$ Reconhecemos as diversas discussões acerca da existência ou não de um sistema de ensino no Brasil (SAVIANI, 1978). Todavia, apoiando-nos na atual legislação educacional brasileira, optamos por adotar o termo "sistema de ensino" para nos referirmos ao conjunto de instituições de ensino (federais, estaduais e municipais) que se inter-
} 
se de um documento que refletiu o movimento político e educacional iniciado na Primeira República, e intensificado com o Movimento Escolanovista, em que os assuntos referentes à educação começaram a ganhar ênfase devido ao reconhecimento de sua importância como instrumento necessário para elevar o nível cultural da nação e fortalecer o campo da produção técnico-científica, visando à aquisição de capital econômico.

Apesar de ser considerado um importante movimento que motivou diversas reformas no campo educacional brasileiro e permitiu diversas conquistas - especialmente no que se refere à ampliação progressiva do acesso à educação pública e gratuita -, presenciou-se, no mesmo período, a oferta de modelos de ensino distintos: de um lado um ensino destinado à formação das elites, que ocupariam as instâncias decisórias do país; do outro, um ensino voltado às camadas populares, que serviriam ao desenvolvimento econômico ao serem convertidas em mão de obra qualificada. Paradoxalmente, este movimento - que não será detalhado neste texto - refletiu o forte dualismo na oferta da educação pública, ainda presente nos dias atuais, e que ainda se coloca como um dos grandes desafios a ser superado.

Cabe ressaltar ainda que, apesar das marcas inscritas neste período da educação brasileira, com exceção da Constituição de 1937, todas as constituições posteriores indicaram a necessidade de elaboração de um plano nacional que viesse estabelecer ações a serem empreendidas no sentido de garantir a todos o acesso ao ensino público nos diferentes níveis e modalidades.

Em 1962, na forma de um documento base publicado após a promulgação da primeira Lei de Diretrizes e Bases da Educação Nacional (LDBEN, Lei 4.024/61) foi elaborado o primeiro PNE, como iniciativa do Ministério da Educação e Cultura, aprovado pelo Conselho Nacional de Educação. Embora não tenha sido proposto no formato de um projeto de lei, o primeiro PNE chegou a estabelecer um conjunto de metas quantitativas e qualitativas a serem alcançadas em um prazo determinado de oito anos. Elaborado para atender a demanda legal da CF de 1946, este plano exerceu apenas "o papel de instrumento de aplicação dos recursos financeiros pelos entes federados". (VALENTE; COSTA; SANTOS, 2016).

Conquanto as metas formuladas não tenham sido concretizadas, o compromisso com a universalização do ensino, por meio da articulação dos entes federados, estabeleceu-se como eixo fundamental do plano nacional, e passou a ser cada vez mais reforçado nos planos subsequentes devido aos acordos firmados entre o Brasil e os organismos internacionais que, progressivamente, definir "meios para uma atividade coletiva intencional" que as transformem em uma unidade. 
transformaram a educação brasileira em um grande palco de disputas entre dois projetos divergentes: de adequação aos parâmetros educacionais delineados pelos grandes centros de poder que representam, eminentemente, os interesses econômicos; e de atendimento às necessidades emergenciais brasileiras denunciadas pelos diversos movimentos educacionais preocupados com questões como a redução da desigualdade social pela via de um ensino público, laico, gratuito e de qualidade.

Com a promulgação da Constituição Federal, em 1988, o prazo de atendimento das metas foi ampliado para dez anos e estabeleceram-se algumas metas a serem contempladas (art. 214), tais como: a erradicação do analfabetismo, a universalização do atendimento escolar, a melhoria da qualidade do ensino, a formação para o trabalho, a promoção humanística, científica e tecnológica do país, bem como, o estabelecimento de meta de aplicação de recursos públicos em educação como proporção do produto interno bruto. Além de contemplar este conjunto de metas, é atribuída à União a obrigatoriedade de colocá-lo em execução no prazo estabelecido.

Após a promulgação da nova LDBEN (Lei 9.394/96) - que, em seus artigos $9^{\circ}$, inciso I, e 87, parágrafo primeiro, consolidou a incumbência da União de elaborar o PNE -, ingressaram, no Congresso Nacional, o Projeto de PNE da sociedade brasileira (PL 4.155/98), seguido por intensos debates e processos de consultas a entidades civis, e o PNE do Executivo (PL 4.173/1998). Ambas as propostas culminaram na Lei 10.172/2001, assinada no governo do então presidente Fernando Henrique Cardoso, em que se instituiu o Plano Nacional de Educação (2001-2010). Para os autores Valente, Costa e Santos (2016, p. 33), ambos os Projetos, que orientaram a instituição deste documento,

[...] se caracterizam, no primeiro caso, pela ampla participação social e pelo caráter de política e ideológica que exprimiu, enquanto que, no segundo caso, pelo comprometimento com a racionalidade administrativa das políticas educacionais do MEC.

Não entraremos em detalhes deste processo, que podem ser conhecidos por meio da leitura de diversos textos acadêmicos, em que se inclui o texto dos autores acima referidos, que se debruçam sobre esta temática. Todavia, consideramos importante registrar que o PNE (2001-2010) refletiu, em suas 295 metas, os embates ideológicos e políticos que caracterizaram todo o seu processo de tramitação. Resultante deste movimento, instituiu-se um plano repleto de contradições, em que se viram incorporadas diversas demandas históricas da sociedade brasileira ao lado da alarmante ausência de definição da maneira como seriam disponibilizados recursos financeiros imprescindíveis ao alcance das metas indicadas, revelando a falta de vontade política do Estado brasileiro. (SAVIANI, 2014, p. 38). 
Inserido no bojo das políticas neoliberais, o PNE priorizou o atendimento das normas internacionais focando, quase exclusivamente, na oferta do ensino fundamental, por meio de programas de financiamento, como o Fundescola, ${ }^{3}$ que auxiliaram a garantia da oferta deste nível de ensino nos sistemas estaduais e municipais. Deste modo, não é possível avaliar e compreender o processo de execução do PNE sem considerar as ações realizadas pelos outros entes federados. (DOURADO, 2010).

O exposto até o momento nos permite considerar que o PNE é resultado de um processo histórico e social, com avanços e retrocessos. Todavia, o período que se instalou após a promulgação da atual LDB, indubitavelmente, colocou o Plano Nacional de Educação num patamar de elevada importância devido ao contexto reformista que se intensificou no Brasil durante a década de 1990 e perdura até os dias atuais.

Em 2014, assistimos a aprovação do novo PNE que, diferentemente do plano anterior, apresentou um conjunto de 20 metas e 170 estratégias, superando a fragmentação dos objetivos e permitindo maior foco nas metas consideradas prioritárias para os próximos dez anos. No próximo tópico, procuraremos apresentar algumas características fundamentais deste novo documento e refletir sobre as possíveis contradições que emergem do processo de execução que prevê a autonomia dos sistemas de ensino para o delineamento de ações asseguradoras do alcance das metas, ao mesmo tempo em que não esclarece como serão disponibilizados os recursos para cumprimento desta tarefa. Deste processo contraditório, emergem políticas de responsabilização, próprias de práticas gerencialistas, que vêm se constituindo como modelo nos processos de implementação das políticas educacionais brasileiras.

\section{O NOVO PLANO NACIONAL DE EDUCAÇÃO (2014-2024): ENTRE A AUTONOMIA E A RESPONSABILIZAÇÃO}

A elaboração do novo PNE (2014-2024), marcada por sensos e contrassensos, deu-se por meio de movimentos democráticos em que se destaca a Conferência Nacional de Educação -

\footnotetext{
3 "O Fundo de Fortalecimento da Escola (Fundescola) é um programa do FNDE realizado em parceria com as secretarias estaduais e municipais de Educação das regiões Norte, Nordeste e Centro-Oeste, com financiamento do Banco Mundial e do Tesouro Nacional. O objetivo do programa é promover a eficácia, eficiência e eqüidade no ensino fundamental público das regiões Norte, Nordeste e Centro-Oeste, por meio da oferta de serviços, produtos e assistência técnico-financeira inovadores e de qualidade, que focalizam o processo de ensino-aprendizagem e as práticas gerenciais das escolas e secretarias de Educação". Texto disponível em: <http://www.fnde.gov.br/fnde/sala-de-imprensa/noticias/ item/1323-banco-mundial-e-fnde-avaliam-fundescola $>$.. Acesso em: 5 maio 2016.
} 
CONAE. ${ }^{4}$ Definida como um espaço de discussão e deliberação coletiva, a CONAE, inicialmente, foi organizada por meio de conferências municipais, intermunicipais, estaduais e distrital, durante o ano de 2013, de onde emergiram diversas propostas presentes no atual PNE. Neste sentido, a CONAE merece destaque, pois significou um movimento de amplo exercício democrático, constituído por diversos atores pertencentes aos mais variados segmentos sociais, principalmente, os da área educacional. (DOURADO, 2015).

O novo PNE traz no corpo de sua Lei 14 artigos em que se apresentam as 20 metas que orientarão as políticas educacionais do próximo decênio. A Lei aponta para nove diretrizes gerais que, incontestavelmente, atendem aos anseios daqueles que se dedicam à melhoria da escola pública brasileira. São elas: a erradicação do analfabetismo; a universalização do atendimento escolar; a superação das formas de desigualdades educacionais e discriminação; a melhoria da qualidade de ensino; a formação para o trabalho e cidadania; a gestão democrática da escola pública; a promoção humanística, científica, cultural e tecnológica; a valorização dos profissionais da educação; e os princípios do respeito aos direitos humanos, à diversidade e sustentabilidade.

Este conjunto de diretrizes assinala a necessidade de um planejamento eficiente por parte dos entes federados que passam a ser responsabilizados, na figura dos gestores regionais e locais, pela efetivação das metas em seus respectivos sistemas de ensino. Trata-se, portanto, de metas que impactam diretamente a figura do Dirigente Municipal de Ensino - DME, responsável por conduzir o processo de elaboração e execução de políticas públicas voltadas ao cumprimento das referidas metas.

Por se tratar de cargo de indicação política, cuja natureza prevê ações orientadas ao atendimento de demandas provenientes da esfera governamental em detrimento daquelas advindas das comunidades escolares e da sociedade em geral, não encontramos trabalhos acadêmicos que se dediquem ao estudo das ações empreendidas por estes sujeitos para além das críticas à sua posição executora das diretrizes oficiais. Embora não desconsideremos a influência da natureza do cargo de Dirigente Municipal nas práticas administrativas, apoiamo-nos em autores que buscam compreender as organizações não apenas como espaços de reprodução normativa, mas de criação de normas advindas do próprio processo administrativo em que, muitas vezes, é necessário o descumprimento das regras formais, por meio de estratégias que permitem o alcance de metas predeterminadas por vias não previstas, portanto, não controláveis. (LIMA, 2008). Diante da

\footnotetext{
${ }^{4}$ Foram realizadas duas Conferências (CONAE), a primeira em 2010, e a segunda em 2014. Será dada mais ênfase a segunda por ter como tema o PNE (2014-2024).
} 
ampliação das políticas regulatórias, nosso interesse se volta à compreensão dos modos como as políticas de materializam por meio da observação de seu processo, neste caso, com foco na ação dos Dirigentes Municipais pela posição importante que ocupam tanto no delineamento dos planos municipais quanto na sua execução.

Lembramos que as políticas que instituem processos de responsabilização se assentam num modo de conceber a Administração educacional e escolar em que o "dirigente" ou "diretor" ocupa um lugar central na condução das ações voltadas à oferta dos serviços pelas instituições de ensino. Trata-se de uma concepção que se reflete na centralização dos processos de tomada de decisão e ainda está arraigada nas práticas de gestão da escola atuais, oriundas da própria tradição escolar. (PARO, 1986; FÉLIX, 1984).

Outra questão que merece atenção neste processo de responsabilização diz respeito às rígidas formas de controle e fiscalização a que estão submetidos os gestores, inclusive, no que se refere à cobrança de alcance de altos índices municipais voltados à avaliação da qualidade do ensino. Ressalta-se, como exemplo, a ameaça de penalização aplicada aos gestores municipais, pelo Tribunal de Contas do Estado e Ministério Público, que poderá ser reforçada caso o Projeto de Lei 7.420/2006 (Lei de Responsabilidade Educacional), principalmente em seu art. $4^{\text {o }}$, venha a ser aprovado.

As críticas contundentes a esses instrumentos de avaliação recaem, principalmente, sobre o fato de desconsiderarem as adversidades que afetam os sistemas de ensino brasileiros e apresentarem possibilidades iminentes de conversão de indicadores quantitativos em dispositivos de controle das ações apreendidas pelos sujeitos.

Ao tentar compreender as causas que levam os indivíduos a aderirem a este "culto da qualidade" nas organizações, Gaulejac (2007) apresenta alguns pressupostos componentes da ideologia gerencialista desenvolvida, sobremaneira, no decorrer dos anos 1990, em que idealizações humanas, como "o desejo de progredir", são utilizadas como estratégia para a manipulação dos indivíduos visando ao alcance de metas. Para o autor, a canalização desses ideais, no sentido de transformá-los em motivações internas para o aumento da produtividade, só é possível porque as pessoas envolvidas nesse processo não têm clareza a respeito daquilo que elas realmente desejam alcançar. Trata-se, portanto, de desenvolver e produzir conceitos difusos referentes à qualidade almejada pela organização que se propagam por todo o espaço formando discursos circulares que se entrecruzam e dão a ilusão de serem termos evidentes formando o que o autor denomina de 
"equação mágica": "qualidade $=$ excelência $=$ desempenho $=$ comprometimento $=$ satisfação das necessidades $=$ responsabilização $=$ reconhecimento $=$ qualidade...” $($ GAULEJAC, 2007, p. 82 $)$.

Nesses termos, a polissemia que envolve a concepção de qualidade torna-se favorável à organização que se assume como sua produtora. O discurso a respeito da qualidade, conquanto seja um discurso destituído de clareza, coerência e objetividade, tem o poder de motivar os indivíduos à busca incessante pelo aperfeiçoamento do próprio trabalho e ao alcance de metas produzidas que, quando alcançadas, são rapidamente substituídas por novas metas num processo que gira apenas em torno de si mesmo. Desse modo, os termos que definem a qualidade nessas avaliações de controle de desempenho são termos marcados pela falsa evidência e portadores de múltiplas significações.

Eles apresentam uma representação positivista da organização que causa a erosão das contradições, dos conflitos e da complexidade. Eles se apresentam como "objetivos" e neutros ao englobar em uma construção abstrata as oposições de interesse, as diferenças de pontos de vista sobre as finalidades, as diferenças entre o prescrito e o real. Não se trata, portanto, de um discurso construído a partir de hipóteses que são colocadas em discussão, de métodos que permitem validar ou invalidar as formulações propostas, mas de um discurso operatório, cujo objetivo é melhorar os resultados [...] (GAULEJAC, 2007, p. 90-91).

Construído a partir de um modelo ideal, o sentido do trabalho se distancia da realidade concreta e passa a ser orientado por indicadores preestabelecidos que normalizam as ações dentro das organizações. Esta adesão voluntária a ideais impostos para a escola resulta de estratégias governamentais que incluem processos de formação continuada para gestores educacionais subsidiados por cartilhas carregadas de discursos sentimentalistas que levam os membros das instituições a assumirem um compromisso individual, quase missionário, na busca por uma educação de qualidade.

As políticas de responsabilização, orientadas pelas avaliações que geram os chamados “índices educacionais”, entre outras prerrogativas já existentes, reforçam a centralização da gestão educacional que passa a ser justificada pela iminente responsabilização e punição legal de um só indivíduo. Tal acometimento contraria a própria Constituição Federal (1988), a Lei de Diretrizes e Bases da Educação Nacional (Lei 9.394/96), e o PNE (Lei 13.005/2014), que explicitam a concepção de Gestão Democrática da Educação, respeitando-se as realidades locais e seus movimentos.

O contexto marcado por políticas regulatórias reforça o exercício de um modelo de gestão fundamentado nos princípios da Teoria Geral da Administração (TGA), onde impera a figura do gerente representante do poder central que determina os caminhos a serem traçados e se é responsabilizado por seus resultados. A transposição deste modelo de gestão no campo da gestão 
educacional/escolar vem sendo criticada nos estudos em Administração Escolar desde a década de 1980. Nas palavras de Paro (1998, p. 135),

[...] A dimensão gerencial permite ao Estado um controle mais efetivo das múltiplas atividades que se realizam na escola, na medida em que se concentra na figura do diretor a responsabilidade última por tais atividades, fazendo-o representante dos interesses do Estado na instituição. O diretor escolar assume assim o papel de "preposto" do Estado, com a incumbência de zelar por seus interesses; estes, embora no nível da ideologia se apresentem como sendo de toda a população, bem sabemos que se constituem em interesses da classe que detém o poder econômico na sociedade.

Entende-se que a função do Dirigente Municipal de Ensino - DME assemelha-se àquela analisada por Paro (1998) referente ao diretor escolar. Como cargo que corresponde ao exercício de Secretário Municipal de Educação ou Chefe de Departamento de Educação Municipal, dependendo da estruturação da rede de ensino, o Dirigente passa a ser visto, igualmente, uma figura central na gestão da Rede Municipal de Ensino.

Um exemplo desta gestão centralizada é o próprio processo de elaboração do PNE e sua materialização no formato de Planos Municipais de Educação (art. $8^{\circ}$ da Lei 13.005/2014). Construído por meio de comissões, os PME foram coordenados pelos DME que se encarregaram de acompanhar e direcionar a elaboração do documento em todas as etapas, juntamente ao chefe do executivo municipal, responsabilizando-se pela garantia de articulação de políticas públicas para alcance das metas em curto, médio e longo prazo. Delega-se a ele, portanto, a responsabilidade de garantir que o sistema de ensino cumpra os dispositivos legais na garantia de acesso e permanência na escola, bem como em objetivos mais específicos que visem assegurar a qualidade da educação escolar. A estratégia 11 da meta 20 do PNE reforça esta afirmação:

[...] aprovar, no prazo de 1 (um) ano, Lei de Responsabilidade Educacional, assegurando padrão de qualidade na educação básica, em cada sistema e rede de ensino, aferida pelo processo de metas de qualidade aferidas por institutos oficiais de avaliação educacionais. (BRASIL, 2014)

O Plano Nacional de Educação trouxe mudanças quase que imediatas para a gestão municipal, uma vez que os municípios, de acordo com o art. $8^{\circ}$ da Lei 13.005/2014, deverão elaborar, no prazo de um ano, seu próprio Plano Municipal de educação alinhando-o às metas dos Planos Nacional e Estadual de Educação.

Sabemos que a busca pela equidade e pela qualidade da educação em um país tão desigual como o Brasil é uma tarefa que implica políticas públicas de Estado que incluam uma ampla articulação entre os entes federativos. Vivemos atualmente um momento fecundo de possibilidades, com bases legais mais avançadas e com a mobilização estratégica dos setores 
públicos e de atores sociais importantes neste cenário. É possível realizar um bom trabalho de alinhamento dos planos de educação para fazermos deste próximo decênio um virtuoso marco no destino do nosso País. (MEC/SASE, 2014, p. 07).

De acordo com orientações do Ministério da Educação, os Dirigentes Municipais de Ensino precisam superar a visão fragmentada de gestão da própria rede ou sistema de ensino. Para isso, é fundamental que se desenvolva uma concepção sistêmica de gestão no território e que se definam formas de operacionalização. (MEC/SASE, 2014).

As análises de documentos oficiais do Ministério da Educação com orientações para elaboração do PME mostram que a concepção sistêmica de Administração escolar ainda tem fundamentando a prática administrativa, conforme defendeu Myrtes Alonso, em 1979, na reconhecida obra "O papel do diretor na Administração Escolar".

Dentro desta concepção desenvolve-se uma tendência a encarar a estrutura e a organização escolar como um complexo sistema de relações [...] Sistema neste caso pode ser entendido como determinado conjunto de em que se efetue uma função completa; esse mesmo sistema pode ser visto, entretanto, como parte de outro sistema quando a função a ser analisada corresponde a uma função do sistema mais abrangente. (ALONSO, 1979, p. 137).

Observa-se que são muitos os desafios da Gestão Municipal. Dentre eles, destacam-se a tarefa de gerir o processo de formulação e implantação do PME de forma democrática, com o devido alinhamento às prerrogativas do plano nacional, e empreender esforços na garantia de uma Educação Pública de qualidade para todos. O problema que se levanta é: existe compatibilidade entre uma abordagem sistêmica de gestão, que preza mais pela responsabilização do que pela colaboração, e um processo de tomada de decisões coletivo, conforme os princípios da gestão democrática?

Esta problemática suscitou o empreendimento deste artigo que, entre outros objetivos, assumiu o esforço de analisar os desafios e as contradições nos processos de elaboração e execução dos planos municipais de educação, no contexto do plano nacional de educação.

\section{OS DESAFIOS DOS DIRIGENTES MUNICIPAIS DE ENSINO NO ALINHAMENTO DO PNE AO PME: DA AUTONOMIA CONSTRUÍDA PARA A AUTONOMIA DECRETADA?}

O conceito de "autonomia construída" corresponde ao que Barroso denomina de "jogo de dependências e de interdependências que os membros de uma organização estabelecem entre si e com o meio envolvente e que permitem estruturar a sua ação organizada em função de objetivos coletivos próprios”. (BARROSO, 1996, p. 185). 
Nesta concepção, a autonomia se reafirma como expressão social e política derivada da interação dos diferentes atores numa determinada organização. Neste sentido, compreendemos que, no jogo de relações que se estabelece no processo de execução de uma determinada política educacional, a autonomia deve ser construída a partir da própria realidade local. Todavia, não se trata de pensar a escola ou o sistema num sentido "micro", mas de promover a devida e necessária relação entre a organização responsável por este processo e o sistema macrossocial representado pelas instâncias governamentais que, em tese, determinariam não apenas a política em si, mas as ações empreendidas para que ela se efetive em todos os espaços.

Embora a execução do PNE seja de responsabilidade de todos os sistemas de ensino em regime colaborativo, diversas metas por ele previstas não poderiam ser incluídas nos PME, pois entrariam em contradição com a própria legislação educacional que estabelece o que é da competência de cada ente federado, como é o caso da Meta 12 que estabelece a elevação de $50 \%$ da taxa bruta de matrícula na educação superior. Neste caso, caberia aos sistemas de ensino municipais, com a devida mobilização social dos atores que o compõem, refletirem sobre os desafios educacionais pertinentes à sua função e à sua realidade, no sentido de priorizar as necessidades locais, identificadas por meio do diálogo com a coletividade, e, num exercício democrático, estabelecerem metas e estratégias que possam, de fato, ser concretizadas ao mesmo tempo em que cobrariam dos entes federados o cumprimento das metas que a eles competem.

Entretanto, ao realizar uma análise dos PME de 14 municípios da região noroeste do estado de São Paulo, identificamos 11 planos que incluem metas de difícil concretização, pois tratam, exclusivamente, de níveis de ensino que não são de responsabilidade dos municípios. As metas $12 \mathrm{e}$ 13, que perspectivam a ampliação de matrículas na educação superior e do número de mestres e doutores nas instituições de ensino superior são encontradas nos planos seguidas de estratégias idênticas às elencadas no plano nacional. Ainda que os municípios encontrassem formas de colaborar com a efetivação destas metas, as estratégias por eles definidas deveriam ser amplamente estudadas para que pudessem ser efetivadas, por meio de rigorosos processos de fiscalização, de modo que não prejudicassem o alcance de metas emergenciais de competência da esfera municipal. Os planos revelam, portanto, a sobreposição do cumprimento burocrático ao processo.

As questões que levantamos a partir destes dados são: seriam estes documentos resultados de uma cultura administrativa ancorada nos pressupostos que consideram os gestores locais "prepostos" do Estado? Teriam os gestores municipais autonomia e competência para traduzir o documento federal, levando em consideração a realidade local? Se sim, quais são os maiores impedimentos? 
Visando responder, ainda que provisoriamente, estas questões, consideramos que a construção da autonomia sugere três tipos de intervenções apontadas por Barroso (1996): a primeira consiste na promoção da cultura da participação e colaboração entre todos, incluindo a própria formulação dos objetivos; em segundo lugar, é preciso considerar que nenhuma intervenção autônoma ocorre sem a escolha de representantes que, conhecendo amplamente a realidade local, assumam a mediação do processo e trabalhem no sentido de promover ações coletivas que estimulem o comprometimento de todos não apenas com o processo de execução, mas também com a fiscalização e acompanhamento destas ações; por último, o exercício da autonomia pressupõe o conhecimento, pelos atores, das regras e da estrutura que governam a instituição. Deste modo, os atores fariam a construção de sua autonomia, culminando num processo de mobilização social autêntico.

Contudo, na ausência dos pressupostos necessários ao exercício desta autonomia, os documentos oficiais do Ministério da Educação passam a exercer forte influência no delineamento dos PME. Ao exigir, sob a óptica da cooperação entre os entes federados, o alinhamento dos planos municipais aos planos nacionais e, sincronicamente, estabelecer mecanismos de responsabilização, desconsiderando o que, de fato, coloca-se como competência dos municípios, o MEC abriu precedentes para que muitos gestores locais incluíssem nas metas dos PME estratégias que, na conjuntura legal existente no país, seriam de competência dos Estados e do Governo Federal, transformando estes precedentes em marcos legais municipais.

Para agravar ainda mais este cenário, o Ministério da Educação criou, no interior de sua estrutura, mais precisamente na Secretaria de Articulação com os Sistemas de Ensino (SASE), a Diretoria de Cooperação dos Planos de Educação, que, através de Avaliadores Educacionais indicados pela União dos Dirigentes Municipais de Ensino (Undime) e pelas Secretarias de Estado da Educação, orientaram o planejamento e a execução do PME, e, posteriormente, a inserção dos planos no Sistema de Monitoramento e Controle do Ministério da Educação (Simec). Os planos migraram do Simec para o site, onde já se encontram disponíveis para download e consulta pública. Estas orientações reforçam nossa análise a respeito da intervenção no exercício da autonomia dos sistemas municipais, conforme demonstrado no seguinte trecho:

O PNE foi organizado em 20 metas, que se fizeram acompanhar de estratégias indispensáveis à sua concretização, reforçando a concepção sistêmica da educação. As metas são estruturantes e passíveis de serem acompanhadas pela sociedade brasileira, e as estratégias são procedimentos para que União, estados e municípios, em colaboração, se organizem para atingir as metas. Tão importantes quanto estes objetivos são as diretrizes do corpo da lei. Elas representam o consenso histórico de forças políticas e sociais no País, que devem balizar 
todos os planos, desde sua elaboração até sua avaliação final. O PNE apresenta também dispositivos que vinculam os planos locais ao nacional, reforçam a necessidade de organização colaborativa das redes ou sistemas de ensino para que as metas sejam atingidas e apontem para formas de acompanhamento e avaliação. (MEC/SASE, 2014, p. 13). (Grifos nossos).

Na análise de Lima (2003, p.36), o que se presencia é um processo de centralização das decisões no âmbito de um Poder Central, representado pelo Ministério da Educação, que, além de delinear metas e estratégias universais, cria os mecanismos de controle político-administrativo em escala nacional a todos os municípios, configurando um "centralismo educativo" que resiste, inclusive, aos propósitos reformistas.

O discurso amplamente difundido entre os dirigentes municipais, que motivou ainda mais este centralismo, relaciona o PME ao Plano de Ações Articuladas (PAR) (Lei 12.695/2012) ${ }^{5}$ considerado, na atualidade, instrumento primordial para obtenção de recursos financeiros e assistência técnica do Ministério da Educação. Esta relação é reforçada por meio do SIMEC que acrescentou, recentemente, a inserção do PME como pré-requisito para o preenchimento diagnóstico do Novo PAR. Deste modo, os municípios que não sancionaram a Lei do PME ficaram impedidos de prosseguir o preenchimento deste Sistema e, consequentemente, de receber recursos provenientes do Governo Federal. Outro item que nos chamou a atenção neste Sistema diz respeito a um campo específico criado para que os municípios apresentem suas justificativas no caso de alguma meta contida no plano nacional não ter sido contemplada no plano municipal. Daí a compreensão da obrigatoriedade dos municípios contemplarem em seus planos as metas nacionais, ainda que estas não estejam de acordo com suas competências.

O que vemos, portanto, é a inversão do processo. Ora, se a não oficialização de um plano substancial como PME passa a ser utilizada como instrumento punitivo que interfere na obtenção de financiamento quando, ao contrário, a garantia ou não de recursos financeiros é que deveria

\footnotetext{
5 “O PAR é uma ferramenta de planejamento para as secretarias de Educação municipais e estaduais brasileiras. Basicamente, os municípios e estados avaliam seus problemas na rede de ensino, reportam ao MEC e recebem assessoria técnica e recursos para implementar mudanças. Municípios e estados fazem uma autoavaliação com base em ações listadas pelo MEC. São quatro áreas: gestão educacional; formação de professores e de profissionais de serviços e apoio escolar; práticas pedagógicas e avaliação; infraestrutura física e recursos pedagógicos. A etapa seguinte é a análise técnica feita pela Secretaria de Educação Básica do MEC e pelo FNDE. Terminada, o município assina um termo de cooperação, que detalha a participação do ministério: com aconselhamento técnico ou assistência financeira. Se há transferência de recursos, o município assina um convênio, que é analisado a cada ano". Texto disponível em: <http://www.todospelaeducacao.org.br/reportagens-tpe/21559/perguntas-e-respostas-o-que-e-e-como-funciona-o-par〉. Acesso em: 28 maio 2016.
} 
orientar, em primeira ordem, a elaboração dos planos municipais, de que autonomia estamos falando? É possível desempenhar autonomia numa estrutura que converte o regime de colaboração em regime de dependência e subordinação?

Para melhor compreensão do que vem sendo exposto até o momento, dividimos as metas do PNE em cinco agrupamentos, de acordo com as suas especificidades, interdependências, campo das políticas públicas, e, ainda, considerando o pacto federativo vigente (Regime de Colaboração entre a União, os Estados e os Municípios), em que cada meta pode estar inclusa, conforme observado no quadro abaixo:

\begin{tabular}{|l|l|l|}
\hline GRUPO & METAS & SÍNTESE DAS METAS \\
\hline A & 01 a 11 & $\begin{array}{l}\text { Direito à Educação, com qualidade, garantia do acesso e } \\
\text { permanência, universalização da Alfabetização, ampliação da } \\
\text { escolarização e oportunidades educacionais, inclusive aos que } \\
\text { não tiveram acesso em idade própria, redução das desigualdades } \\
\text { educacionais e valorização da diversidade. Trata de todas as } \\
\text { etapas de ensino inerentes à Educação Básica. }\end{array}$ \\
\hline $\begin{array}{l}\text { Ensino Superior } \\
\text { B }\end{array}$ & 12 a 14 & $\begin{array}{l}\text { Refere-se exclusivamente às políticas de acesso e qualidade do } \\
\text { Ensino Superior, e ainda da formação dos professores que atuam } \\
\text { neste nível de ensino. }\end{array}$ \\
\hline $\begin{array}{l}\text { Educação } \\
\text { Crofissionais da }\end{array}$ & $\begin{array}{l}\text { Valorização dos profissionais da educação, com a equiparação } \\
\text { salarial aos demais profissionais com escolarização equivalente, } \\
\text { política nacional de formação, piso salarial nacional, jornada de } \\
\text { trabalho, e plano de carreira. }\end{array}$ \\
\hline $\begin{array}{l}\text { Gestão Democrática } \\
\text { Financiamento da }\end{array}$ & 19 & $\begin{array}{l}\text { Efetivação da gestão democrática na escola pública, a ocorrer } \\
\text { num prazo de dois anos da aprovação do PNE. }\end{array}$ \\
\hline $\begin{array}{l}\text { Educação } \\
\text { Qinanciamento da educação, com vistas ao alcance do patamar } \\
\text { de 7\% do PIB (Produto Interno Bruto) no primeiro quinquênio e } \\
\text { de 10\% até o final do decêncio. }\end{array}$
\end{tabular}

Quadro 1: Divisão das metas em cinco grupos. (AUTORES, 2016).

Ao analisarmos o quadro, tomando por referência a gestão municipal, consideramos que os grupos de metas “A", “C" e "D" seriam, significativamente, contemplados nos níveis e modalidades correspondentes à sua competência, considerando ainda, o pacto federativo. O grupo de metas "B", por sua vez, distancia-se da maioria das realidades municipais, por tratar, exclusivamente, do Ensino Superior. Obviamente, a inexistência de instituições de ensino superior em grande parte dos municípios brasileiros não os isenta de traçar algumas medidas para colaborar com estas metas, no entanto, responsabilizar-se pelo seu cumprimento seria arriscado em um contexto de recursos, muitas vezes, insuficientes. Este risco, de certo modo, poderia ser corrigido caso o grupo de metas "E” culminasse em estratégias que resultassem em garantias de recursos suficientes para atender a 
demanda de cada município de acordo com a sua realidade. Entretanto, o que se observa é o incentivo para a criação de mecanismos de monitoramento dos gastos públicos com educação, na lógica mercantilista de "custo-benefício", que acaba por contradizer o próprio princípio de gestão democrática, uma vez que os gestores são levados a atuar mais como controladores do orçamento do que como representantes educacionais que atuam, por tempo determinado, como administradores de recursos públicos de modo transparente e com a autonomia necessária para que estes recursos venham, de fato, atender as necessidades locais, visando à promoção de um ensino de qualidade. Uma vez limitados estes recursos, aos administradores compete, junto com a categoria que representam, exigir do poder público o cumprimento de seu papel que consiste em garantir verbas suficientes ao alcance das metas previstas; e não há outra via para o exercício desta função que não seja a gestão democrática. De outro modo, a autonomia se converte em um álibi para sustentar a ideia de que educação de qualidade se faz com a "boa vontade" e a "boa gestão" de um único indivíduo; dinheiro é apenas um detalhe...

Uma das explicações possíveis para que muitos municípios tenham aderido a metas que não condizem com sua realidade e competência, pode ser encontrada nos chamados estudos em "nível mesoanalítico", que compreendem as organizações educativas como espaços em que as metas advindas dos órgãos superiores são muitas vezes reproduzidas estrategicamente, visando ao cumprimento das exigências burocráticas, não sendo possível garantir, sequer prever, meios que assegurem sua efetivação. O excesso de normativas que visam controlar a ação dos sujeitos num contexto em que os recursos são escassos, faz com que, na prática, os indivíduos façam reinterpretações de tais regras, produzindo regras não-oficiais, exercendo o que Lima (2003) denomina de "infidelidade normativa". Cabe ainda analisar como esta infidelidade está sendo exercida in loco e que resultados poderão gerar no período de vigência do novo PNE. 


\section{REFERÊECIAS:}

ALONSO, Myrtes. O Papel do Diretor na Administração escolar. Rio de Janeiro: Educ Difel, 1979.

BARROSO, João. O Estudo da Escola: da autonomia decretada à autonomia construída. In: BARROSO, João. (Org). O Estudo da Escola. Lisboa: Porto Editora, 1996.

BRASIL. Constituição (1988). Constituição da República Federativa do Brasil. Diário Oficial da União. Brasília: Congresso Nacional, 05 out. 1998. Anexo. Disp.: <www.planalto.gov.br/ccivil_03/Constituicao/Constituicao.htm>. Acesso: 10 jul. 2016

BRASIL. Lei 9.394, de 20 de dezembro de 1996. Estabelece as diretrizes e bases da educação nacional. Diário Oficial da União. Brasília: Poder Legislativo, 23 dez. 1996, sec. I, n. 248, p. 27.833. Disp.: <www.planalto.gov.br/ ccivil_03/leis/L9394.htm>. Acesso em: 08 jul. 2016

BRASIL. Lei 10.172 de 09 de janeiro de 2001. Aprova o Plano Nacional de Educação. Diário Oficial da União. Brasília, DF: Poder Legislativo, 10 jan. 2001, p. 01. Disp.: <www.planalto.gov.br/ccivil_03/leis/L9394.htm〉. Acesso: 08 jul. 2016.

BRASIL. Lei 13.005, de 24 de Junho de 2014. Aprova o Plano Nacional de Educação - PNE. Diário Oficial da União. Brasília, DF: Poder Legislativo, 26 jun. 2014, p. 01, Edição Extra. Disp.: <http://www.planalto.gov.br/ccivil 03/ ato2011-2014/2014/lei/113005.htm>. Acesso em: 16 abr. 2016.

DOURADO, Luis Fernandes. Plano Nacional de Educação, Conferência Nacional de Educação e a Construção do Sistema Nacional de Educação: dilemas e proposições. In: CALDAS, Andréa. O Plano Nacional de Educação e o Sistema Nacional de Educação: Livro 1. 1. ed. Curitiba: Appris, 2015.

FÉLIX, Maria de Fátima Costa. Administração Escolar: um problema educacional ou empresarial. São Paulo: Cortez: Autores Associados, 1984.

GAULEJAC. V. Gestão como doença social: ideologia, poder gerencialista e fragmentação social. Aparecida, SP: Ideias e Letras, 2007.

LIMA, Licinio C. A escola como organização educativa: uma abordagem sociológica. 3. ed. São Paulo: Cortez, 2008.

MINISTÉRIO DA EDUCAÇÃO. Secretaria de Articulação com os Sistemas de Ensino. Planejando a próxima década: conhecendo as 20 metas do Plano Nacional de Educação. Brasília: MEC/SASE, 2014.

Secretaria de Articulação com os Sistemas de Ensino. Planejando a próxima década: alinhando os planos de educação. Brasília: MEC/SASE, 2014.

Secretaria de Articulação com os Sistemas de Ensino. Plano Municipal de Educação: Caderno de orientações. Brasília: MEC/SASE, 2014.

PARO, Vitor Henrique. (1986). Administração Escolar: introdução crítica. 15. ed. São Paulo: Cortez, 1998.

SAVIANI, Dermeval. Sistema Nacional de Educação e Plano Nacional de Educação: significado, controvérsias e perspectivas. Campinas. Autores Associados. 2014. (Col. Polêmicas do Nosso Tempo).

VALENTE, Lucia F.; COSTA, Maria Simone P.F.; SANTOS, Fernando Henrique. Nas trilhas do planejamento educacional e seus contornos nas políticas de educação no Brasil. In: Revista Brasileira de Política e Administração da Educação, vol. 32, n. 1, 2016. 


\section{RESUMO}

A aprovação do novo Plano Nacional de Educação - PNE (2014-2024) gerou impactos imediatos à Educação Pública em todos os entes federados. Neste artigo, buscaremos refletir acerca do impacto do PNE no âmbito da gestão dos municípios, diante da exigência de formulação dos chamados Planos Municipais de Educação (PME). As contradições identificadas, tanto nas orientações para o processo de elaboração dos PME quanto nos próprios planos, permitem considerar que as metas advindas dos órgãos superiores estão sendo reproduzidas estrategicamente, visando ao atendimento das exigências burocráticas, não sendo possível garantir, sequer prever, meios que assegurem sua efetivação.

Palavras-chave: Plano Nacional e Municipal de Educação; Gestão Educacional; Autonomia dos Sistemas de Ensino.

\section{ABSTRACT}

The approval of the new National Education Plan - NEP (2014-2024) has originated immediate impacts to Public Education in all federated entities. In this article, we reflect on the impact of the NEP in the scope of city government, faced with the demand of the elaboration of the so called Municipal Education Plan (MEP). The contradictions that were identified, not only in the process of elaborating the MEP but also in the plans themselves, allow us to consider that the goals originated from higher governmental bodies have been produced strategically, aiming at bureaucratic fulfillments and therefore not being able to guarantee, or even to predict, means which might assure its effectuation.

Keywords: National and Municipal Education Plan; Education Management; Education System Autonomy.

Submetido em Jul./2016

Aprovado em Nov./2016 